https://doi.org/10.21670/ref.1820020

Artículos

\title{
¿Ciudades gemelas? Posadas, Argentina y Encarnación, Paraguay en perspectiva sociourbana
}

\section{Twin cities? Posadas, Argentina and Encarnación, Paraguay in socio-urban perspective}

Recibido el 5 de julio de 2018.

Aceptado el 27 de noviembre de 2018.

Publicado el 11 de diciembre de 2018.

*Autor para correspondencia: Walter Fernando Brites, correo electrónico: briteswalter@yahoo. com.ar

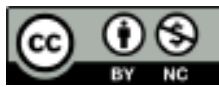

Esta obra está protegida bajo una Licencia Creative Commons Atribución-NoComercial 4.0 Internacional.
Walter Fernando Brites ${ }^{\text {** }}$ (i) https://orcid.org/0000-0003-2801-5792

a Universidad Nacional de Misiones, Instituto de Estudios Sociales y Humanos; Consejo Nacional de Investigaciones Científicas y Técnicas, Posadas, Argentina, correo electrónico: briteswalter@yahoo. com.ar

\section{Resumen}

El objetivo de este artículo es evidenciar los procesos de relacionamientos complementarios que mantienen las ciudades fronterizas de Posadas, Argentina y Encarnación, Paraguay. Desde un abordaje descriptivo y diacrónico el estudio sostiene que estas ciudades pueden ser interpretadas como ciudades gemelas que comparten una historia de relaciones en el contexto regional. Al margen de sus especificidades, ambas ciudades presentan aspectos sociourbanos similares, y en su devenir estuvieron implicadas en los mismos procesos y problemas: flujos fronterizos, políticas del Mercosur, construcción del puente internacional, acuerdos de Tránsito Vecinal Fronterizo, y hasta un fenómeno más inusual, como la impronta que grandes obras de infraestructura han dejado en sus territorios. Se concluye que estas ciudades, a pesar de no contar con un gobierno común, sostienen relaciones económicas, culturales, de vecindad y complementariedad que producen impactos en una ciudad y viceversa, generando interdependencias, mutuos condicionamientos y una forma específica de articulación interurbana.

Palabras clave: conurbación, intercambios, espacios de flujos, complementariedad.

\section{Abstract}

The objective of this article is to demonstrate the mechanisms of complementary relationships maintained by the border cities of Posadas, Argentina and Encarnación, Paraguay. From a descriptive and diachronic approach the study argues that these cities can be interpreted as twin cities, which share a cultural and historical matrix in the regional context. Both cities apart from their specificities, present similar socio-urban aspects, and in their evolution they were involved in the same processes and problems: border flows, Mercosur policies, construction of the international bridge, Border Neighborhood Traffic Agreements, even a more unusual phenomenon, such

CÓMO CITAR: Brites, W. F. (2018). ¿Ciudades gemelas? Posadas, Argentina y Encarnación, Paraguay en perspectiva sociourbana [Twin cities? Posadas, Argentina and Encarnación, Paraguay in socio-urban perspective]. Estudios Fronterizos, $19, \mathrm{e} 020$. doi:https://doi.org/10.21670/ref.1820020 
as the effect that large infrastructure works have left on their territories. It is concluded that these cities, despite not having a common government, the economic, cultural, neighborhood and complementarity relations, generate impacts in a city and vice versa, generating interdependencies, mutual conditioning, and a specific form of inter-urban articulation.

Keyword: conurbation, interchange, flow spaces, complementarity.

\section{Introducción}

Posadas, Argentina y Encarnación, Paraguay, son ciudades que se implican de manera mutua en su desarrollo: sus procesos sociourbanos guardan nexos, tienen un sostenido relacionamiento multipropósito y ambas atraviesan por un condicionamiento recíproco. Además, estas ciudades presentan una serie de características compartidas que las integran de modo inédito en una conurbación transfronteriza. En primer lugar, podemos señalar que se trata de ciudades medias fronterizas, que en sus condiciones de capitales de provincia y departamento respectivamente, han desarrollado un proceso de conurbación, impulsando la dinámica urbana de otras ciudades vecinas de menor escala. En segundo lugar, otra característica singular refiere a la habilitación del puente Internacional San Roque González de Santa Cruz que conecta ambas ciudades. El puente generó un corredor urbano internacional, infraestructura que posibilitó sortear las adversidades del río Paraná y desarrollar un sistema de transporte binacional (taxi, moto taxi, colectivos urbanos, tren, entre otros) que vincula cotidianamente a sus habitantes. La tercera característica, es que ambas ciudades fueron impactadas por el embalse del río Paraná y el consecuente paquete de obras de infraestructuras de defensas costeras desarrolladas por la hidroeléctrica Yacyretá, obras con efectos en acciones de renovación urbana y revalorización en ambas márgenes del río.

Por último, en términos de intercambios socioeconómicos, Posadas y Encarnación no están exentas de una de las características más marcadas que presentan las ciudades gemelas: la proximidad, el desarrollo de interacciones locales y el encontrarse entre relaciones de competencia y cooperación. Este proceso imprime una especial relación entre estas ciudades, a la vez que sumado a otros acontecimientos, reavivan el debate contemporáneo en torno a las ciudades de frontera.

Sin duda, la especial relación que tienen Posadas y Encarnación se remonta al pasado. Son ciudades que nacieron de un mismo proceso sociohistórico y, desde sus orígenes, estuvieron íntimamente ligadas a la frontera compartiendo fluidas interacciones y estrechos vínculos socioeconómicos y culturales. No obstante, como intentaré demostrar, hoy sus inéditas reconfiguraciones socioespaciales, sumado a los espacios de flujos y estructuras de oportunidades acentúan sus características y lógicas complementarias.

El conjunto de características que presentan Posadas y Encarnación pueden ser interpretadas a partir del generalizado modelo de ciudades gemelas; ciudades donde a pesar de no contar con un gobierno común, las relaciones económicas, culturales, de vecindad y complementariedad producen impactos en una ciudad y viceversa, generando interdependencias, mutuos condicionamientos y una forma específica de

articulación interurbana. Por lo tanto, es importante introducir un breve debate sobre los procesos y dimensiones teórico-conceptuales implicados en su abordaje. 


\section{Las ciudades en la frontera: Dilemas conceptuales y aproximaciones}

De forma creciente las ciudades localizadas en fronteras internacionales han sido llamadas de diferentes maneras: ciudades gemelas, ciudades pares, ciudades fronterizas, ciudades binacionales, ciudades dobles, ciudades transfronterizas, ciudades espejo, etc. (Alegría, 2008; Buursink, 2001; Carrión, 2016; Vergel-Tovar, 2008,). La existencia de un límite fronterizo y de una ciudad "par" constituye una condición sine qua non para la emergencia y características que las ciudades van a tomar en uno y otro lado de la frontera. Una de las características de las denominadas ciudades gemelas es presentar flujos transfronterizos (Steiman, 2012), que conlleva la potencialidad de redundar en las condiciones de vida de sus habitantes y ofrecer estructuras de oportunidades asociadas a la localización residencial con impactos en el crecimiento demográfico.

En el planteamiento de estos dilemas conceptuales, merece señalar que al margen de autores con propuestas disímiles, el criterio de la discusión teórica del artículo, es aunar criterios con base en la convergencia de diversos aportes conceptuales significativos para: 1) la comprensión del modelo generalizado de ciudades gemelas y 2) describir las propiedades y características empíricas del caso analizado y sus especificidades.

La noción mediática de ciudades gemelas ha suscitado confusión, en el sentido de la idea de lo símil o idéntico, y precisamente, no debe interpretarse el aspecto de "iguales", pues no existen ciudades que sean estructuralmente o perfectamente iguales. ${ }^{1}$ En términos más consensuados, se consideran ciudades gemelas aquellas que son parte de una frontera internacional, están próximas geográficamente y presentan interacciones locales (Kearney y Knopp, 1995), pudiendo conformar una continuidad urbana. El concepto también implica la idea de culturas, economías y sociedades interrelacionadas (Zavaleta, 1986). Para Carrión (2016) las ciudades "gemelas o espejo" no existen por sí mismas, sino por el vínculo con la del "otro lado", creando una interconexión en los bordes de los Estados. Así, con frecuencia el hecho de que estas ciudades constituyan puntos de contactos entre naciones vehiculiza el intercambio comercial y el aprovechamiento que una hace de la otra. En línea con esta perspectiva, y haciendo uso de una noción biologicista, el concepto de ciudad gemela implica que ambas ciudades tienen una relación simbiótica de igualdad (Peña, 2008). Claro está, de una igualdad en la relación de complementariedad en el vínculo asociativo.

A pesar de que la noción de ciudades gemelas, originalmente aludió a un tipo de aglomeración urbana fronteriza, en los últimos tiempos, se produjeron un refinamiento y desarrollo significativo de este concepto por parte de muchos científicos sociales, para analizar los pares urbanos internacionales. Así, para Tambi (2016) las ciudades gemelas son ciudades fronterizas adyacentes entre sí, y en sus condiciones de vecindad están expuestas a la integración, con lazos bilaterales estables y por lo tanto, pueden desarrollar una agenda en común. Las ciudades gemelas también han sido descritas cuando sus habitantes se visitan recíprocamente de vez en cuando y establecen contactos estables al otro lado de la frontera (Mikhailova, 2013).

\footnotetext{
${ }^{1}$ Esta idea ha llevado a que Vanneph y Revel-Mouroz (1994) postulen que las "ciudades gemelas" son falsas gemelas, son lugares de diferencia y de relaciones diferentes entre ciudades.
} 
Las publicaciones sobre ciudades fronterizas discuten un amplio abanico de temas, desde el desarrollo urbano, los sistemas de gobernanza, las relaciones comerciales hasta las dinámicas interurbanas. La cuestión de la continuidad-discontinuidad urbana ha sido debatida en la delimitación de estas ciudades, así hay posturas que afirman que las ciudades gemelas pueden presentar o no, unificación de la trama urbana con la ciudad del país vecino, pudiendo llegar a ser continuos o discontinuos espacialmente. Otra arista de este debate refiere a la espacialidad física, ligada a un conjunto de flujos, redes y relaciones de índole sociales, económicas, culturales, políticas y ambientales, establecidas entre dos o incluso más ciudades pertenecientes a distintos países (Zárate, 2012).

La ciudad fronteriza encuentra su existencia íntimamente ligada a las actividades de la frontera, y sus dinámicas urbanas interactúan con los márgenes político-administrativos de los países. Las ciudades gemelas, son en efecto ciudades que se enfrentan a través de una frontera internacional y, que por lo tanto, tienen una especial interrelación. De acuerdo con Ehlers, Buursink y Boekema (2001), las ciudades fronterizas, después de años y tal vez siglos de interrelaciones, a menudo se encuentran en un difícil equilibrio de competencia y cooperación, de independencia y dependencia.

Otros aportes conceptuales, para el estudio de fenómenos como el que aquí proponemos, refieren a procesos de conurbación binacional y las implicancias de factores sociourbanos y demográficos (Bustamante, 1981) o, la existencia de complejos urbanos binacionales (Carrión, 2016). Desde una perspectiva interesante, Dilla (2008) propone la noción de Complejos Urbanos Transfronterizos (CUT), para analizar una serie de circunstancias: $a$ ) la representación compartida de una necesidad mutua, $b$ ) la cercanía geográfica, $c$ ) la reproducción económica interdependiente, $d$ ) el sostenimiento de relaciones sociales primarias entre sus pobladores, $e$ ) el compartir variados servicios sociourbanos, culturales y, $f$ ) la existencia de relaciones institucionales, desde el Estado y la sociedad civil. ${ }^{2}$ Desde mi punto de vista, y como definición de indicadores, esta perspectiva es por cierto muy relevante para comprender "algunas" manifestaciones de las ciudades en contexto de fronteras.

Por encima del aspecto físico territorial, como dimensión perceptible de ciudades que se encuentran próximas, lo importante es analizar cómo estas se amalgaman a la frontera y los procesos económicos y socioculturales derivados. La cuestión transfronteriza es crucial, las ciudades en sí mismas reciben la impronta de la frontera que prefigura su naturaleza condicionando su devenir. Como sostiene Herzog (Citado en Dilla, 2015, p. 46) "...las ciudades fronterizas han resultado tan conectadas funcionalmente, que sus futuros están ineludiblemente ligados, independientemente de si los gobiernos nacionales pudieran establecer procedimientos formales para incidir en los problemas fronterizos".

Más allá de la relevancia de los diferentes aportes teóricos aquí presentados, nos inclinamos por el punto de vista de Steiman (2012), para quien las ciudades gemelas aparecen definidas como núcleos urbanos localizados de un lado y otro del límite internacional, cuya interdependencia es con frecuencia mayor de la que cada ciudad pueda tener con su región o territorio nacional. Así como también nos posesionamos en Vergel-Tovar (2008) quien sostiene que no se trata de un asunto de similitudes entre el ambiente construido, o marcos institucionales, sino de espacios sociales creados por

${ }^{2}$ Por otro parte, para Dilla (2008, p. 169) "estos complejos funcionan en medio de contradicciones debido a la prevalencia de asimetrías y diferentes modalidades de intercambio desigual". 
los habitantes fronterizos, que generan procesos simétricos y asimétricos, que definen las características de la frontera.

En otro trabajo (Souza y Brites, 2017), se considera que más allá de los procesos urbanos globales y contemporáneos, las ciudades localizadas en contexto de fronteras internacionales, experimentan procesos sociourbanos de inusitada complejidad y variabilidad. En otras palabras, las ciudades fronterizas adquieren una configuración y dinámicas específicas en su desarrollo y consolidación, desde los entornos del medio urbano construido, hasta las prácticas de sus habitantes, las legislaciones y las políticas internacionales.

Al margen de la literatura aquí propuesta, se considera que las ciudades en contextos transfronterizos se amalgaman a una serie de condiciones y situaciones, que más allá de las relaciones económicas (simétricas, asimétricas, cambiantes), interactúan con los procesos socio urbanos, las políticas (legislaciones) y la singularidad de las estructuras de oportunidades que pueden presentarse en uno u otro lado de la frontera.

En concreto, Posadas-Encarnación reúnen una serie de características, que a la vez, nos proporcionan material para abonar la idea de que ambas pueden ser pensadas como ciudades gemelas, que integran una conurbación transfronteriza con inéditas situaciones y relaciones. Este argumento se basa en las siguientes razones:

- Posadas y Encarnación tienen un origen en común, nacen como reducción jesuítica, y aunque se delimitan en la Guerra de la Triple Alianza (1865-1870), la consolidación urbana de ambas es contemporánea.

- Son ciudades que a pesar de estar separadas por el río Paraná tienen una proximidad geográfica que posibilitó de antaño frecuentes interrelaciones entre las mismas.

- Sus procesos urbanos atraviesan por una continuidad mediada por el límite del río, donde el puente actúa hoy como una cremallera de articulación interurbana.

- Los núcleos urbanos de ambas ciudades asumen la condición de polos de atracción poblacional y desarrollo económico.

- Existen relaciones sociales multipropósito e intensas entre sus pobladores: vecinales, laborales, comerciales y hasta familiares (con cierta recurrencia).

- Las relaciones comerciales son voluminosas, oscilantes (pendulares), sujetas a coyunturas económicas y a las ventajas diferenciales que presenta la frontera.

- Sus habitantes están expectantes de lo que ocurre en una y otra ciudad: tiendas, productos, espacios de ocio, eventos culturales, servicios; lo que alimenta una idea de necesidad mutua.

- Son ciudades, que aunque sometidas a gobiernos distintos, comparten relaciones institucionales, controles de actividades, tránsito vecinal fronterizo, acuerdos, etc.

- Ambas ahondan en una característica: reciben tanto los impactos de la dinámica fronteriza, como los efectos sociourbanos de la hidroeléctrica Yacyretá.

Lejos de constituir una propuesta "integracionista" de ciudades gemelas, considero que Posadas y Encarnación presentan procesos de relacionamientos que están caracterizados por asimetrías y diferencias socioeconómicas y culturales, pero acompañados por lógicas de intercambios complementarios y regulares, por flujos transfronterizos de comercio (tanto formal como informal), oportunidades 
de trabajo, servicios de salud y educación, sistemas de transporte urbano, redes de infraestructuras, entre otros. Un escenario que nos proporciona una compleja realidad urbana-transfronteriza (Figura 1).

Figura 1. Posadas y Encarnación: Núcleos urbanos en contexto de proximidad fronteriza

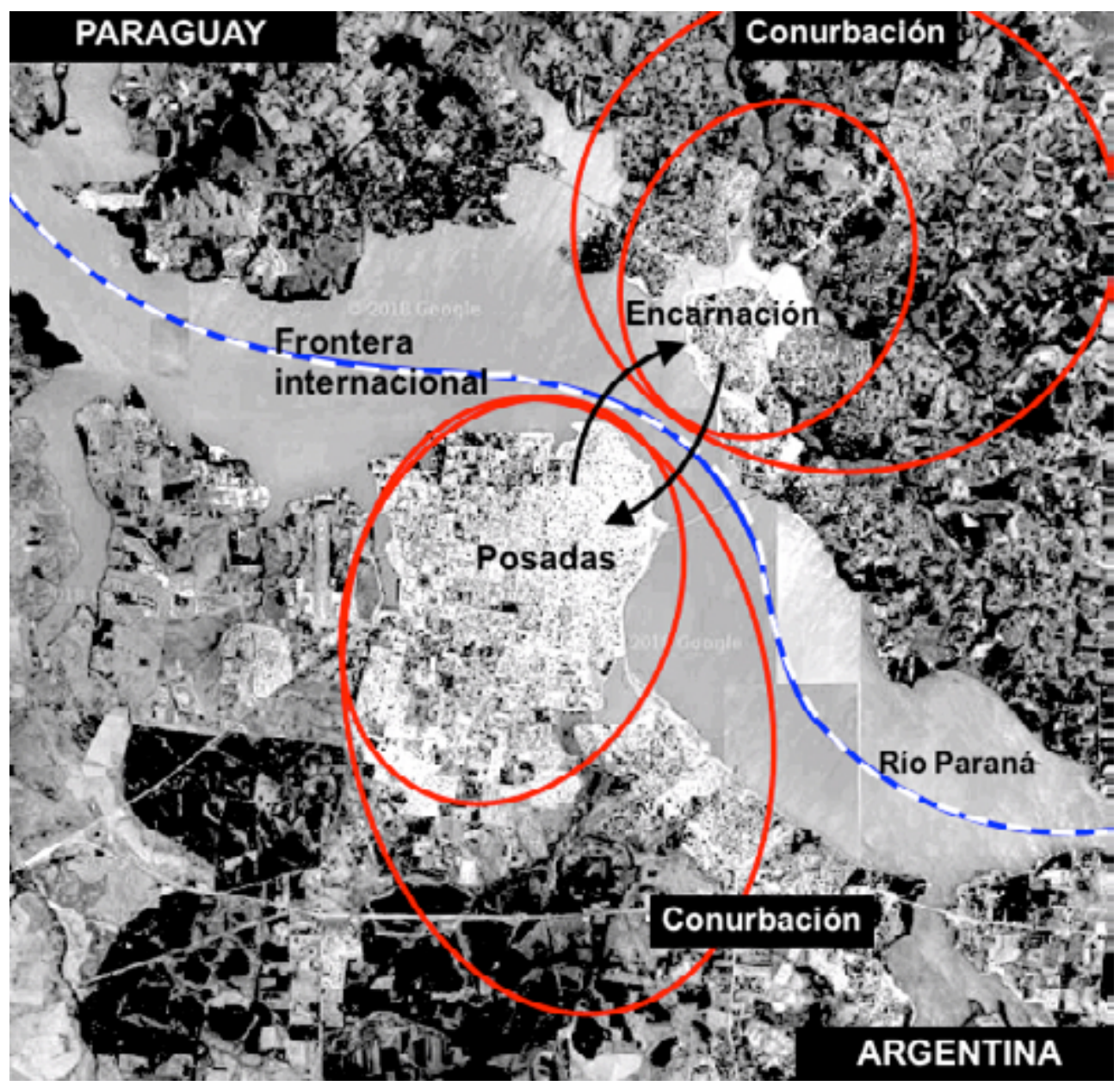

Fuente: Elaboración propia con base en Google Earth.

\section{Metodología del estudio}

Este estudio presenta información original sobre un caso de ciudades medias fronterizas con características inéditas en el contexto regional. Puede decirse que constituye una aproximación exploratoria, anclada en un abordaje descriptivo y diacrónico que presenta evidencias empíricas que posibilitan interpretar a estas conurbaciones 
con base en el modelo de ciudades gemelas. ${ }^{3}$ Para la investigación se recabaron y analizaron diferentes fuentes de información: documentos y archivos oficiales y no oficiales, notas de periódicos locales, tratados binacionales, planes y políticas de desarrollo, legislaciones municipales de ambas ciudades, etc. Por otro lado, en la fase de investigación de campo se realizaron entrevistas semiestructuradas a diversos informantes como: aduaneros, choferes de ómnibus, taxistas, paseros, comerciantes, vendedores ambulantes, y de modo más específico conversaciones con habitantes de ambas ciudades y discusiones con otros investigadores.

A nivel general, la investigación avanzó con el planteamiento de preguntas a fin de comprender la dinámica de los procesos de relacionamientos, intercambios y complementariedades entre ambas ciudades. En este sentido, se recurrió a un análisis comparativo en torno a diversas dimensiones referidas al puente Internacional, los cambios en el espacio urbano, los flujos y movilidades, las dinámicas de intercambios, las estructuras de oportunidades transfronterizas, entre otros procesos sociourbanos que se manifiestan en las ciudades de Posadas y Encarnación.

\section{La transformación de Posadas-Encarnación}

\section{Ciudades fronterizas con escenarios de conurbación}

En sintonía con las ideas de que las ciudades de fronteras son organizadoras de regiones transfronterizas y que asumen la condición de crecimiento poblacional y desarrollo económico (Carrión y Llugsha, 2013), podemos sostener que Posadas y Encarnación como ciudades fronterizas, integran una nueva conurbación en límites internacionales. Encarnación constituye un nodo urbano, generando junto a otras pequeñas ciudades (Cambyretá, Capitán Miranda, Fram, Carmen del Paraná y San Juan del Paraná) una pequeña área conurbana. Del mismo modo, del lado argentino, una de las características de Posadas es su cercanía con las ciudades de Garupá y Candelaria, ampliando su mancha urbana en el eje sur. Estas ciudades hoy dependen de las estructuras de oportunidades (bienes y servicios) disponibles en las ciudades de referencia.

En su consolidación urbana hacia la década de 1960, ambas ciudades comenzaron a recibir procesos migratorios rural-urbanos de pobladores que abandonaban el campo y las actividades agrícolas para instalarse en la ciudad, motivados por las incipientes ventajas que presentaba la vida urbana: eran los núcleos urbanos y comerciales que más habían crecido, lo que posibilitaba trabajos, servicios, comercios, energía eléctrica, etc. Una migración, que de hecho también fue transfronteriza ya que una parte sustancial de las clases populares de Posadas era proveniente del Paraguay (Abínzano, 1985; Bartolomé, 1983; Pobreza Urbana [Pobur], 1989).

\footnotetext{
${ }^{3}$ Esta propuesta no comparte el criterio de interpretación de Cossi (2013), precisamente por el foco en el paso fronterizo y no considerar las variadas implicaciones de la proximidad geográfica así como los procesos de imbricación social y económica, que son en rigor, empíricamente suficientes y analíticamente relevantes para sostener a Posadas-Encarnación como ciudades gemelas que integran una conurbación binacional.
} 
Actualmente Posadas con 360000 habitantes y Encarnación con 121335 habitantes (Dirección General de Estadísticas, Encuestas y Censos [DGEEc], 2015) amplían sus áreas conurbanas. Además, como capitales de provincia y departamento respectivamente, son sedes de gobernación, concentran la administración pública y los servicios, situación que conjuntamente al crecimiento demográfico y del mercado de trabajo, lo constituyen como centro urbano-regional. Esta área metropolitana internacional superó actualmente los 500000 habitantes. Según estimaciones del Instituto Provincial de Estadísticas y Censos (IPEC, 2010; Plan Estratégico Posadas 2022, 2010), en la próxima década este conglomerado de áreas urbanas binacionales constituirá una urbe cercana al millón de habitantes (813 165 habitantes). Esta prospectiva es interesante, teniendo en cuenta que la metropolización como la globalización generan un doble proceso, caracterizado tanto por la homogenización y la diferenciación de los actores sociales, tendiendo a forjar los mismos tipos de actores económicos en todas las ciudades (Ascher, 2001; Lungo, 2011). ${ }^{4}$

Desde la perspectiva de la conurbación (que puede dar lugar a una extensa discusión), Posadas y Encarnación crecen y se expanden más allá de sus límites administrativos, redefiniendo la densidad de su población y la dispersión de sus manchas urbanas. Un proceso que establece nuevas relaciones interurbanas, donde las ciudades asumen dinámicas propias, con lógicas complementarias e interdependientes, organizándose en una inédita región transfronteriza. Un desafío hoy para pensar la ciudad del mañana.

\section{El efecto puente}

La ubicación fronteriza y limítrofe de Posadas y Encarnación es estratégica en la medida en que ha implicado un histórico y fluido intercambio económico y sociocultural entre ambas ciudades, que desde larga data se ha dado vía fluvial, a través del servicio de lanchas (barcos de bandera Argentina-Paraguaya) y buques que cruzaban el caudaloso río Paraná. Una vía de transporte que fue quedando en desuso a partir de la habilitación del puente Internacional en el año 1990 (Figura 2).

A partir de su construcción iniciada en 1983, no solo se dio inicio a una gran expectativa a nivel regional, sino a una fuerte inversión en trabajos de infraestructura y mano de obra. El puente Internacional San Roque González de Santa Cruz, ${ }^{5}$ tiene una longitud total de 2550 metros y se compone de un viaducto carretero y ferroviario, construido sobre el río Paraná.

El puente constituyó una mega obra históricamente anhelada entre ambos países y desarrollada en paralelo a los esperados efectos de la represa Yacyretá, así como a la articulación regional y de las políticas que favorecerían la integración en el marco del Mercosur. Al margen de los tratados binacionales implicados en su construcción, al poco tiempo de su habilitación, el puente posibilitó una inédita articulación territorial

\footnotetext{
${ }^{4}$ Actores que al margen de su procedencia (público-privado, locales-nacionales) se constituyen como agentes financieros, grupos corporativos, desarrolladores, elites, entre otros.

${ }^{5}$ El nombre del puente se debe al padre jesuita Roque González de Santa Cruz, quien fuera fundador de varias reducciones, entre ellas las que ocupan las actuales ciudades de Posadas y de Encarnación. Entre otras anécdotas, el puente obtuvo el premio internacional "Puente de Alcántara" a la obra pública más destacada del perlodo (1989-1990).
} 
entre ambas ciudades. Una situación que constituyó una opción más ágil y directa para la circulación de personas, mercaderías e informaciones que el tradicional servicio de lanchas (Báez, Brites y Espinosa, 2013). En otras palabras, como infraestructura binacional el puente acrecentó y dinamizó la relación socioeconómica y cultural entre Posadas y Encarnación.

Desde la habilitación del puente Internacional Posadas-Encarnación, la interrelación ha sido más acentuada, agilizando la vinculación cotidiana entre residentes de ambas ciudades. Se destacan en este aspecto las asimetrías comerciales, el desarrollo de un mercado de trabajo con ventajas diferenciales, el cruce fronterizo cotidiano de miles de habitantes, la implementación de una oficina de Tránsito Vecinal Fronterizo, un vasto mercado informal vinculado a productos textiles, alimentos y electrónicos y la disponibilidad de un sistema de transporte urbano internacional, que entre otros aspectos, otorgan características muy singulares a esta conurbación internacional. Hacia mediados del año 2017, la Dirección Nacional de Migraciones (Argentina) confirmó que a diario unas 45000 personas en promedio utilizan el viaducto internacional que une Posadas con Encarnación.

El puente se inserta en un espacio transfronterizo donde un número creciente de personas conviven con los controles coercitivos de las legislaciones nacionales y municipales para cruzar la frontera. Esa situación está dando lugar a nuevos desafíos intergubernamentales entre las jurisdicciones de ambas ciudades. Como sostiene Vergel-Tovar (2008, p. 362):

La coexistencia de ciudades fronterizas puede desarrollar problemas comunes para ambas áreas urbanas que pueden ser resueltos mediante la cooperación entre ambas ciudades, o bien, generar escenarios en los cuales ambas compiten por ofrecer servicios en un contexto de economía de mercado global.

Un hecho inédito signa la emergente importancia del puente, ya que diario los habitantes de Posadas-Encarnación suelen estar más expectantes del mismo: saber cómo estará el tránsito en el puente es quizás más relevante que saber que deparará las condiciones climáticas del día. En otras palabras, el puente es una infraestructura supranacional, pero compartida localmente por posadeños y encarnacenos, constituyendo un espacio urbano vívido. Es por otro lado, una vía para el encuentro entre ciudadanos y un facilitador de densas relaciones interurbanas, comerciales, laborales, de supervivencia, etc.

\section{Relaciones de ida y vuelta e intercambios}

Posadas y Encarnación como espacios urbanos transfronterizos, son escenarios complejos para el desafío de conocer las interrelaciones sociales, los vínculos de interdependencias y los procesos complementarios de articulación sociourbana. La proximidad geográfica tiene efectos socioespaciales entre ambas ciudades, a la vez que habilitan estructuras de oportunidades en uno y otro lado de la frontera: capitales, trabajos, tierra, servicios públicos y privados, comercios, etc.; elementos que se aggiornan a la extensa historia de interconexión y de procesos socioculturales compartidos. 
Figura 2. Proximidades urbanas y limítrofes de Posadas y Encarnación

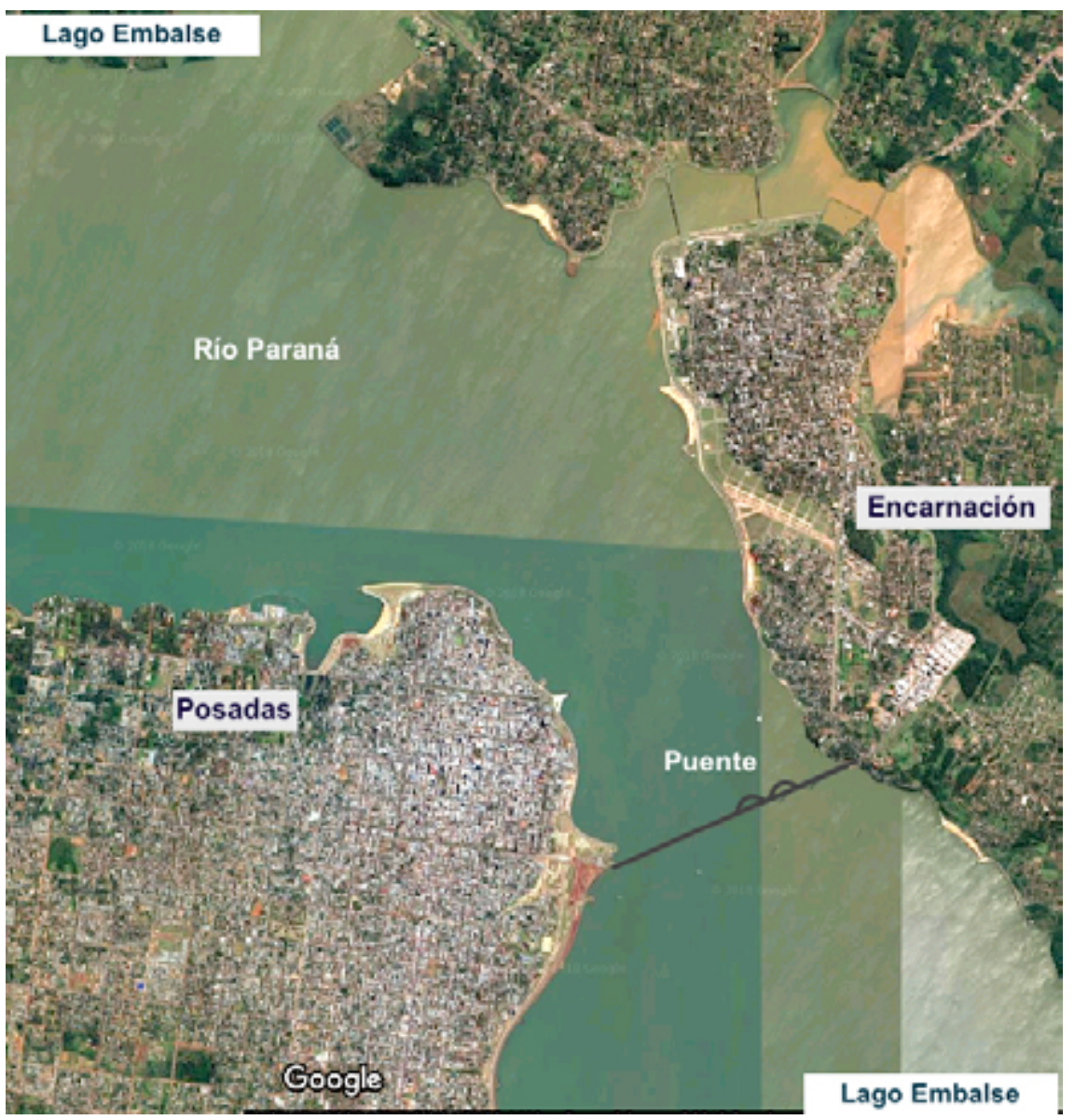

Fuente: Elaboración propia con base en Google Earth.

En muchos casos el pasar la frontera, circular y conocer la ciudad vecina, se convierte en una cotidianeidad y necesidad. Además del tradicional "comercio hormiga" de la pasera paraguaya (Linares, 2017), es común ver en Posadas ciudadanos paraguayos trabajando en la albañilería (construcción), el servicio doméstico, el pase, venta de productos a domicilio, reventa y compra de mercaderías, etc. Del mismo modo, ciudadanos argentinos acuden a Encarnación para la compra de productos (textiles, electrónicos, bazar, repuestos, etc.), para consumo propio o reventa, como una estrategia de maximización de ingresos, aunque también en menor medida, el cruce puede obedecer al empleo en trabajos que demandan mayor calificación (servicios profesionales, docencia, entre otras) ${ }^{6}$

\footnotetext{
${ }^{6}$ Es importante señalar, que al día de hoy, muchos profesores de Posadas dan clases en Encarnación.
} 
Muchas de estas interrelaciones no solamente son intensas en el sentido económico, sino que a veces están amalgamadas a relaciones parentales o familiares. ${ }^{7}$ Fundamentalmente, teniendo en cuenta que los espacios fronterizos son realidades heterogéneas que se constituyen como ámbitos de sociabilidad en permanente transformación (Benedetti, 2011).

Los diferentes periodos y coyunturas económicas (que no es de interés analizarlas aquí en detalle) han incidido en las variantes de los flujos e intercambios entre las dos ciudades, posibilitando nuevas e inéditas interacciones entre sus ciudadanos. Así, por ejemplo, durante la década de los noventa -por citar solo una coyuntura-, la brecha cambiaria entre la paridad peso-dólar y el guaraní produjo una asimetría, un contexto donde la posibilidad de optar por las ventajas diferenciales que ofreció el sistema monetario fronterizo, conllevó a que aflorarán diversas estrategias ligadas a actividades que trascendieron dimensiones laborales y comerciales. Como hecho emblemático, podemos recordar el caso de posadeños que fueron a vivir a Encarnación conservando sus trabajos en Posadas; así como de jóvenes de Posadas que iniciaron sus estudios universitarios en Encarnación, o el de albañiles encarnacenos trabajando en obras de Posadas. Como práctica común, todos ellos cruzaban el puente diariamente.

Desde que el puente las ha unido, estas ciudades han visto reverdecer sus procesos socioeconómicos de forma intermitente y complementaria en uno y otro lado de la frontera. Los intereses y racionalidades de compra-venta han sido notablemente selectivas: desde combustible, cemento, alimentos y medicamentos en unos casos, hasta pintura, vestimenta, cigarrillos y whisky en otros. Estamos hablando de estrategias de compras en ambos lados, según los productos. Este proceso ha vehiculizado en muchos casos relaciones de índole clientelares entre vendedores y compradores. De modo que la intensidad de estas relaciones orbita en el plano de lo económico, y sin olvidar, que también se amalgaman a una serie de prácticas ilegales, legales y cuasiilegales vinculadas al tráfico fronterizo.

Como pobladores de fronteras, posadeños y encarnacenos están sujetos tanto a acuerdos de Tránsito Vecinal Fronterizo como de Tráfico Vecinal Fronterizo, el primero es una bisagra binacional no entre Estados sino entre municipios (Organización Internacional para las Migraciones [OIM], 2018) y autoriza el ingreso, permanencia y circulación por un tiempo de 72 horas, y hasta un radio de no más de 50 kilómetros a la redonda de ambas ciudades; además pudiendo acceder a una credencial de Tránsito Vecinal Fronterizo (TVF). ${ }^{8}$ El régimen de Tráfico Vecinal Fronterizo, es un régimen aduanero simplificado que permite adquirir (comprar) productos para uso personal y del hogar, incluidas prendas de vestir, por un cupo de 150 dólares estadunidenses

\footnotetext{
${ }^{7}$ Los lazos de parentesco (familiares o de compadrazgos) de antaño entre sus pobladores, encuentran diversos orígenes, desde exiliados políticos del régimen del dictador Paraguayo Alfredo Stroessner, hasta población rural pobre de Itapuá que migró a Posadas, cuando esta consolidaba su proceso urbanizador.

${ }^{8}$ Como marco más general, el Tránsito Vecinal Fronterizo está incluido en el ámbito del tratado económico del Mercado Común del Sur (Mercosur), que desde 1991 implica acuerdos de controles aduaneros, uno de ellos estipula la instalación de un sistema de credencial para regularizar la práctica del TVF (MERCoSUR/RMI/ACORDO Nº. 17/99, s.f.).
} 
por persona mensualmente. ${ }^{9}$ Aunque en el relato de las personas que a menudo pasan la frontera, el régimen no es un mecanismo eficaz de control y existen recurrentes estrategias de evasión (comprar y traer productos no permitidos, esconder mercaderías, no declarar, entre otras).

Comoloilustra la Figura 3, en los últimos años, se ha incrementado significativamente el número de personas que cruzan a diario el puente Internacional, y si bien muchos lo hacen en tránsito desde otras ciudades, o por tour de compras, no obstante los movimientos por Tránsito Vecinal Fronterizo entre Posadas y Encarnación ascienden a 55\% (orm, 2018). ${ }^{10}$ Esta forma específica de movimiento alude a desplazamientos cotidianos en ambos sentidos de la frontera, motivados por actividades, relaciones sociales, intercambios múltiples y otras necesidades.

Figura 3. Evolución de los movimientos migratorios anuales Posadas-Encarnación

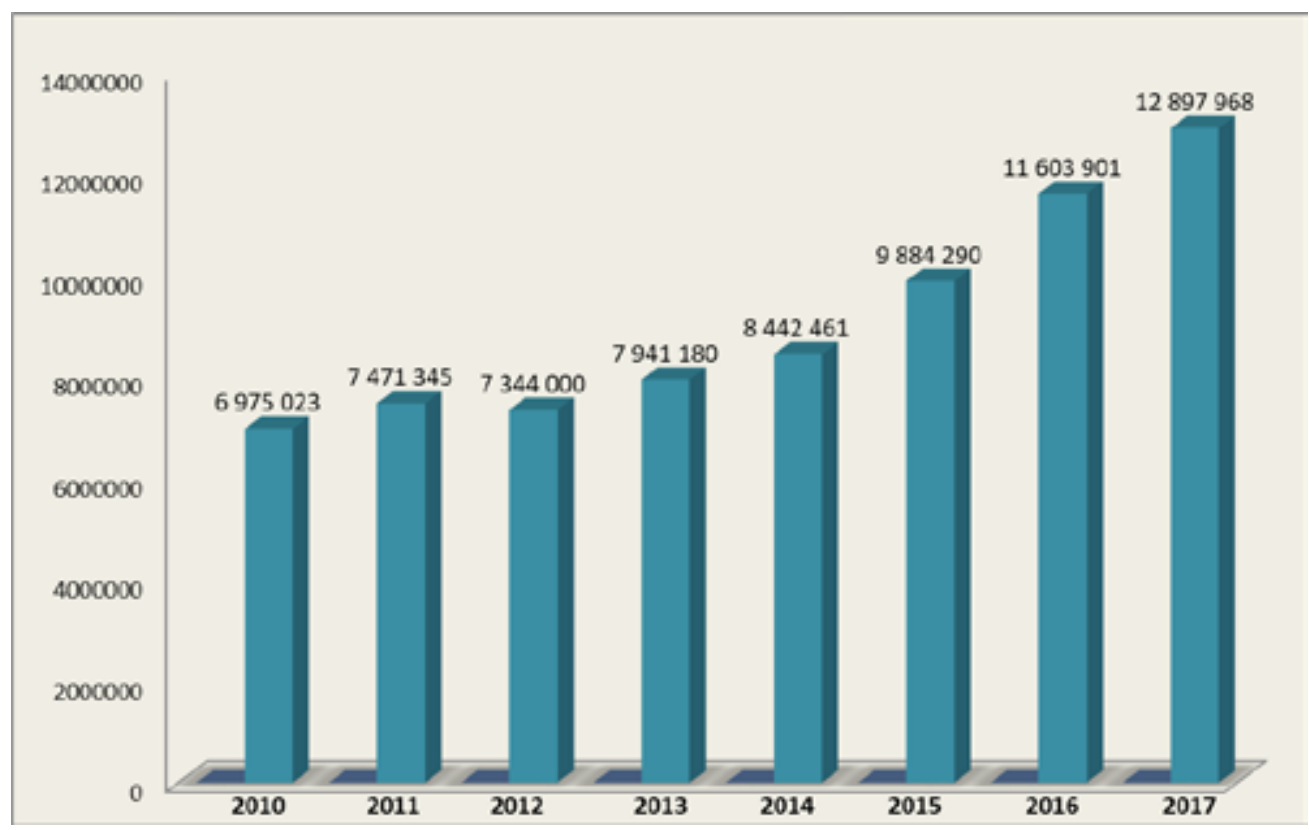

Fuente: Elaboración propia con base en la Dirección Nacional de Migraciones (2017).

\footnotetext{
${ }^{9}$ Si bien la Resolución General № 262 (1998) permitía la compra de artículos para consumo familiar por un monto de us $\$ 150$ dólares estadunidenses, las modificatorias posteriores de la resolución (Resolución General No 1116, 2001, anexo II "A" Normas Generales y el Anexo III "B” Trafico Fronterizo de Importación) restringieron a us $\$ 50$ el cupo de compras en dólares e impusieron gravámenes. Por el lado paraguayo, el Ministerio de Hacienda por el art. 2 de la Ley № 2422 (2004) estableció el valor máximo de ciento cincuenta dólares (US \$150) por mes calendario.

${ }_{10}$ Por el puente también cruzan ómnibus internacionales de larga distancia que unen distintas ciudades del Paraguay con numerosas ciudades de Argentina, por ello estos movimientos (locales e internacionales) explican los porcentajes relativamente parejos de ingresos en categorías TVF y no TVF (OIM, 2018).
} 
A diario en Posadas pueden observarse gran cantidad de automóviles y motos con patentes paraguayas, personas que desarrollan diversas actividades laborales: cruce de mercaderías, flete, venta al menudeo, servicios domésticos, entre otras. Se trata de un aspecto visible de los commuters, como lo descrito por Ojeda (2008), y Herzog (1990) en alusión a trabajadores que viven en un lado de la frontera pero que trabajan en el otro, y que para ello realizan importantes desplazamientos interurbanos y transfronterizos. ${ }^{11}$ Estos desplazamientos cotidianos de una ciudad a la otra, facilitado además por un sistema de transporte urbano compartido, están poniendo en evidencia nuevas formas de relacionamiento, así como procesos de adaptación de los habitantes a las nuevas condiciones sociourbanas, económicas, y culturales derivadas de la articulación entre estas ciudades fronterizas.

Los mercados de Posadas y Encarnación dinamizan formas de movilidad a partir de relaciones comerciales que son voluminosas y complementarias, pero no exentas de conflictos y tensiones. Nos encontramos con situaciones en que comerciantes de Posadas reclaman medidas por la desventajosa competencia comercial con Encarnación, y ciudadanos de Encarnación que venden, compran y acceden a servicios en Posadas, y situaciones casi generalizadas en que ciudadanos -en ambos lados de la fronterapiden más libertad de cruce y menos controles. Dicho de otra manera, las asimetrías comerciales y de servicios no son vistas del todo como graves problemas, sino como una estructura de oportunidades que posibilita el acceso a bienes y servicios diferenciales.

Actualmente, tanto Encarnación como Posadas disponen de servicios, espacios de ocio y entretenimiento que más allá de las motivaciones, magnitudes, sentidos, complejidades y jurisdicciones, son espacios vividos y utilizados entre sus habitantes: hospitales, grandes tiendas, playas, restaurantes, discotecas, casinos, espacios verdes, eventos culturales, carnavales, etc. El conjunto de estas experiencias de cruzar la frontera, compartir servicios, conocer lugares y, participar de procesos sociourbanos, abren un campo de relaciones sociales transfronterizas. ${ }^{12}$ En otras palabras, las relaciones de interdependencia mutua quedan plasmadas en expresiones consuetudinarias y recurrentes entre sus ciudadanos: ¿Qué haríamos si no estuviese Posadas del otro lado! ¡Ir a Encarnación es casi una necesidad!

\section{Movilidad y espacios de flujos. Vivir localmente la frontera}

En el plano de las movilidades, la consolidación de los distritos urbanos de PosadasEncarnación y la densificación de sus actividades, está implicando no solo un incremento del uso del transporte en los trayectos centro urbano-periferia, sino desde estos a la ciudad vecina y sus centros de frontera, teniendo en cuenta que dos empresas de colectivo internacional unen la terminal de ómnibus de Posadas con la terminal de ómnibus de Encarnación. Una situación que contribuye al aumento de la movilidad interurbana (Figura 4).

\footnotetext{
${ }^{11}$ Esta denominación anglosajona de commuters tiene poca posibilidad de traducción al español y deriva del commuting, aunque con frecuencia entendemos a este proceso como movimientos pendulares o cotidianos con motivos laborales, educativos, entre otros (Acuña y Graizbord, 1999).

${ }^{12}$ En esta perspectiva resultan esclarecedores los aportes de Buursink (2001) al distinguir entre los consumidores biculturalistas, que hacen cruces fronterizos regulares para ir de compras o de trabajo y los ciudadanos biculturalistas, que participan en la vida social en ambos lados de la frontera.
} 
Desde hace no más de diez años, la interrelación entre ambas ciudades ha sido más acentuada. Es cada vez mayor el número de personas que cruzan el puente y las filas de automóviles y buses se hacen interminables, también influenciado por la concurrencia de personas de otros lugares que esperan llegar a Encarnación en tours de compras. ${ }^{13}$ Los controles migratorios y de aduanas y las recurrentes largas esperas han enardecido el ánimo de posadeños y encarnacenos que a diario necesitan cruzar la frontera. Esta situación fue poniendo al estado del tránsito sobre el puente como centro de noticas e información diaria en los medios de comunicación. ${ }^{14}$

En la medida en que aumentó la cantidad de personas que cruzan la frontera, fueron surgiendo reclamos y conflictos entre diferentes agentes sociales (transportistas, aduaneros, gendarmes, pasajeros, taxistas, moto-taxistas), lo que despertó la búsqueda de mejores condiciones de movilidad urbana transfronteriza. Hacia el año 2015, para contrarrestar el mayor tiempo de espera, se implementó el servicio de tren binacional como un servicio complementario al transporte urbano internacional, aumentando así la frecuencia de cruces. La formación del tren con capacidad para 190 pasajeros, va y viene de una estación a otra, en un recorrido de diez minutos. Sin embargo, a pesar de las medias adoptadas, el denso volumen de vehículos y la cantidad de personas en las cabeceras del puente ha ido en aumento (Tabla 1). Actualmente, se debaten nuevas alternativas que agilicen la movilidad transfronteriza, como la construcción de más casillas, horario corrido, ampliación de vagones del tren, controles integrados, etc.

Tabla 1. Pasajeros transportados en tren entre Posadas-Encarnación

\begin{tabular}{|c|c|}
\hline Años & Pasajeros movilizados \\
\hline 2015 & 832042 \\
\hline 2016 & 1407545 \\
\hline 2017 & 1508718 \\
\hline
\end{tabular}

Fuente: Comisión Nacional de Regulación del Transporte (CNRT) 2017.

En los últimos tiempos, pese a la alta concurrencia, el amontonamiento y la congestión vehicular en la frontera, miles de personas cruzan el puente diariamente, incluso es recurrente ver que muchas de ellas lo hacen varias veces al día, usufructuando el régimen de Tránsito Vecinal Fronterizo, realizando trayectos cortos, de ida y vuelta, pasando mercaderías, entrando y saliendo de la ciudad y del país. Tal hecho es curioso en la frontera, porque además de develar inéditas prácticas, pone de relieve la intensidad de la interacción y de los intercambios materiales y humanos.

${ }^{13}$ En los últimos años, la devaluación de la moneda argentina y la diferencia cambiaria ha estimulado a nivel regional y nacional la realización de tours de compra en Encarnación.

${ }^{14}$ Para más información consultar http//www.misionesonline.net (27 julio de 2016), nota: El éxodo a Paraguay pone en peligro la estructura del puente que une Posadas-Encarnación. 
Figura 4. Flujos transfronterizos Posadas-Encarnación

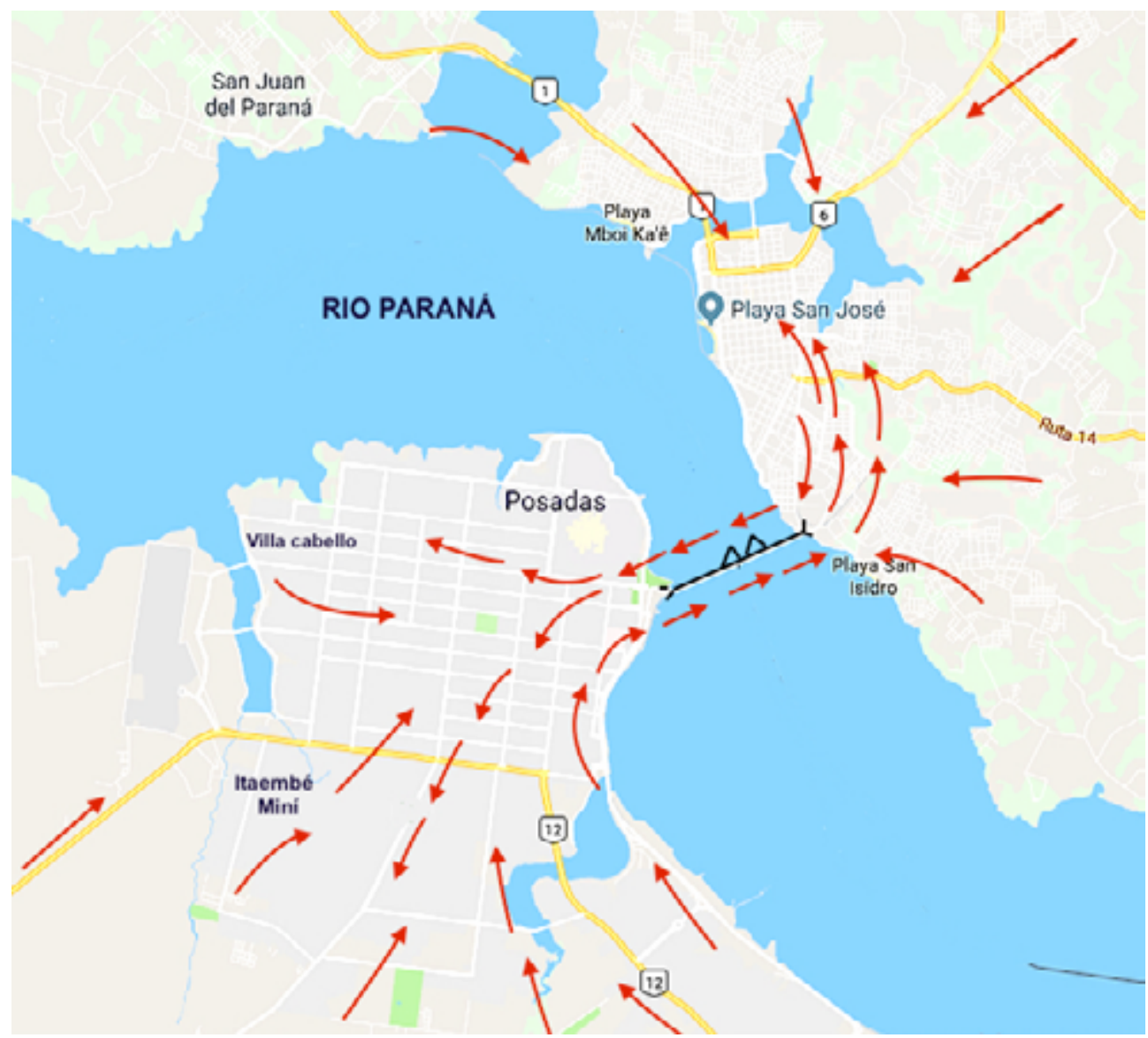

Fuente: Elaboración propia con base en Wikimapia.

A pesar de los intermitentes descontentos de comerciantes posadeños por las asimetrías comerciales con Encarnación, la mayor parte de los residentes de ambas ciudades claman por el mejoramiento de la infraestructura de integración física y las vías de comunicación interurbanas. Una situación que recientemente puso en evidencia estos reclamos, fueron los movimientos de oposición al denominado mediáticamente "muro de la vergüenza". Un muro construido (5 metros de altura por 1500 metros de extensión lineal) en el centro de frontera de Posadas, destinado a endurecer los controles migratorios y aduaneros. Sin embargo, dos años después, los persistentes reclamos obligaron a la demolición de parte del muro, a fin de facilitar una mejor vía de comunicación entre las dos ciudades.

\section{Relaciones bilaterales de cooperación}

Los regímenes de Tránsito y Tráfico Vecinal Fronterizo, muy focalizados en el aspecto económico, son solamente una parte visible de los acuerdos bilaterales de cooperación, 
no obstante, con cierta intermitencia ambas ciudades establecen vínculos transfronterizos locales -con distintos grados de formalización-, a fin de resolver problemáticas de incumbencia para la gestión del relacionamiento fronterizo e interurbano.

En los últimos años, han sido reiteradas las ocasiones en que Posadas y Encarnación desarrollaron agendas en común para unificar criterios de control, agilizar el cruce fronterizo, evitar largas esperas para cruzar, mejorar la vinculación, etc. La complejidad de estos problemas, ha implicado que estas ciudades no solo tejan vínculos transfronterizos de cooperación intermunicipal (entre autoridades locales), sino que desarrollen vínculos institucionales a diferentes escalas, que van desde la Cámara de Comercio e Industria de Posadas, la Gobernación de Itapúa, Ministerios de Relaciones Exteriores (Comercio Exterior), Aduanas, hasta la Entidad Binacional Yacyretá, involucrándose con frecuencia el sector privado y otras instituciones de nivel intermedio.

Aunque los mecanismos de integración funcionan desde hace mucho tiempo, quizás las relaciones bilaterales quedaron más plasmadas a partir de la conformación de un Comité de Integración Posadas-Encarnación en el año 2013. ${ }^{15}$ Un acuerdo interinstitucional donde la cuestión del Tráfico Vecinal Fronterizo y los problemas de integración fueron debatidos en el marco de comisiones que abordaron temas relativos a: migraciones, transporte y aduanas, comercio y turismo, cooperación policial y seguridad, cultura y educación, desarrollo social y salud. Además de acuerdos específicos de vigilancia epidemiológica conjunta, control sanitario y el mejoramiento de la infraestructura en los límites fronterizos.

Los vaivenes en la intensidad del relacionamiento y los flujos interurbanos entre Posadas y Encarnación gravitan en las oscilaciones económicas y la disparidad cambiaria entre Argentina y Paraguay. Un proceso que da lugar a retirados problemas en la movilidad pendular entre las dos ciudades, lo que deriva en frecuentes reclamos, protestas y entrega de petitorios a autoridades (en ambos lados), para solucionar el lento paso fronterizo. Más recientemente (diciembre 2017), las autoridades paraguayas han vuelto a oír los reclamos de ciudadanos encarnacenos y por medio del Ministerio de Relaciones Exteriores han convocado a autoridades de la Argentina con dependencia en Posadas para reforzar compromisos bilaterales en materia de infraestructura, logística, migraciones, gestiones consulares, controles aduaneros y otras actividades realizadas en los pasos fronterizos del puente internacional.

Es interesante observar que la diplomacia de estas ciudades gemelas en particular, difiere de los intereses y acuerdos que persiguen los estados a los que pertenecen. Supongo que los acuerdos bilaterales entre Posadas-Encarnación son un instrumento de vital importancia para promover "acercamiento e integración"; generando un proceso inusual, en el que el acercamiento de los Estados se da en segundo plano, a partir de las necesarias relaciones de proximidad entre estas ciudades y, en el que los problemas locales ayudan a traer a los gobiernos nacionales (Figura 5).

\footnotetext{
${ }^{15}$ Reunión celebrada en la ciudad de Encarnación el 21 de octubre de 2013, acción llevada a cabo en conjunto entre el Consulado General de Argentina en Encarnación y el Consulado General de Paraguay, en Posadas; el acta final fue firmada en Posadas el 22 de julio de 2016.
} 
Figura 5. Esquema de relaciones interurbanas Posadas-Encarnación

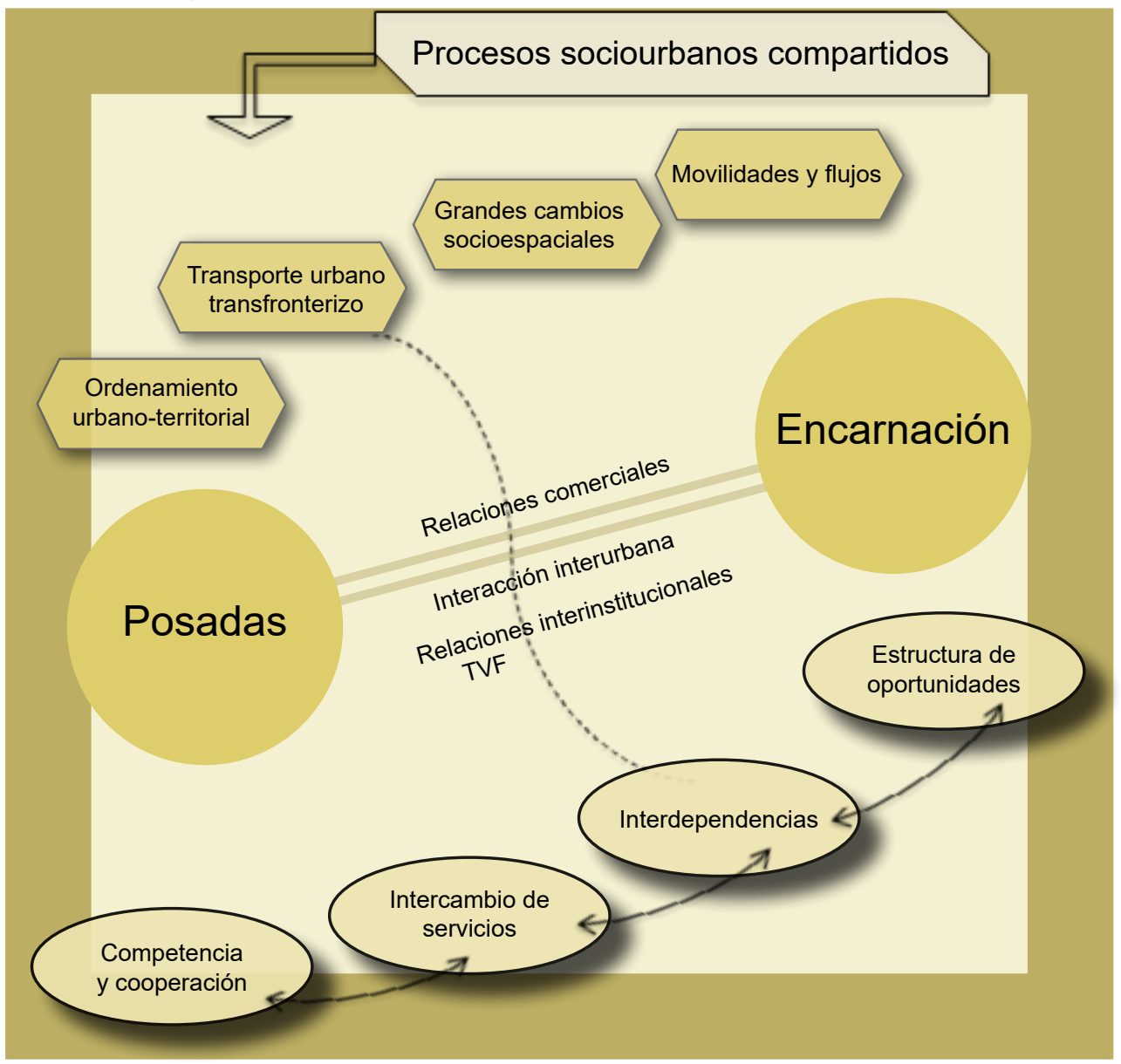

Fuente: Elaboración propia.

\section{Cambios en el espacio y nuevos procesos sociourbanos}

Como conurbaciones en crecimiento, resulta imposible analizar las transformaciones socioespaciales de Posadas y Encarnación sin hacer alusión a los efectos de la represa de Yacyretá, no solo por los cambios en la morfología urbana de estas ciudades (anegamiento y desaparición de vastas áreas), sino por el desarrollo exponencial de grandes obras públicas de reposición de infraestructura (defensas costeras, tratamiento medioambiental, construcción de conjuntos habitacionales, relocalización de miles de familias). Tanto en Posadas como en Encarnación, la mayor parte de las barriadas pobres que ocupaban las costas bajas y anegadizas del río Paraná y otros espacios próximos a la centralidad urbana han sido relocalizados hacia otros puntos distantes en ambas ciudades.

Los cambios en el nuevo frente fluvial, las características de las obras costeras, los espacios habilitados, y los nuevos procesos de segregación y diferenciación socioespacial han hecho que estas ciudades, en sus disposiciones urbanísticas, experimenten los 
mismos procesos socioespaciales. Tanto Posadas como Encarnación, veinte años atrás no solo tenían una trama urbana más unificada, sino que sus territorios eran más compactos y densificados. Hoy en día la mancha urbana se ha extendido, pero no solo por procesos inherentes al crecimiento demográfico, sino por procesos de desplazamientos hacia nuevas áreas de periferia y por la habilitación de nuevos barrios de viviendas que a modo de manchas se multiplican aisladamente sin una adecuada vinculación o conexión con otras áreas.

La nueva reconfiguración de la trama urbana de ambas ciudades ha derivado en nuevas centralidades, espacios de alto valor económico y simbólico, pero también en nuevas periferias (Brites, 2014). ${ }^{16}$ La remoción de población y las obras costeras han habilitado variadas intervenciones de renovación urbana: dotación de grandes ramblas, plazas y espacios verdes con equipamiento urbano, arborización del paisaje costero, etc.; un proceso donde los sectores de mayor poder adquisitivo fueron disputando a otros sectores sociales, la ocupación del espacio conforme a la mejora del entorno que realizaron las obras públicas. En otras palabras, puede decirse que, Posadas y Encarnación transformaron simultáneamente sus espacios urbanos como efecto de Yacyretá.

Los principales problemas en términos territoriales, se concentran en la gran extensión con que se desarrollan ambas ciudades y la marcada desigualdad entre áreas de vacíos intersticiales, falta de servicios y las áreas dotadas de los mejores equipamientos urbanos. ${ }^{17}$ En el contexto de estas transformaciones urbanas emergen variadas formas de desplazamientos, territorialización de prácticas sociales, segregación y diferenciación de unos sectores sociales por otros.

Los grandes cambios espaciales de Posadas y Encarnación gravitan en torno a las acciones de la hidroeléctrica Yacyretá y al cambio en su nuevo frente fluvial. Tres observaciones podrían señalar convergencias y poner en eje de análisis a estas ciudades gemelas:

1. Grandes cambios urbanísticos y paisajísticos, sobre todo en su frente fluvial (Costanera, parques, espacios verdes, playas, entre otros).

2. El surgimiento de nuevas normativas y legislaciones de ordenamiento urbano territorial con similares acciones de renovación sobre el frente costero (Plan Encarnación Más, 2016; Plan Estratégico Posadas 2022, 2010; Plan Urbano Ambiental Posadas, 2012).

3. Renovación y revalorización urbana, desarrollo de nuevos emprendimientos inmobiliarios con efectos de sustitución social y movilidad residencial en la ocupación del espacio urbano (gentrificación, segregación y otras).

Los aspectos antes descritos, resultan esclarecedores para comprender como estas dos ciudades transfronterizas se transforman en simultáneo, experimentando cambios

\footnotetext{
${ }^{16}$ Periferias que refieren a las afueras de la ciudad, la vida en zonas distantes o de escasez de servicios urbanos, un proceso que se da en emergencia a nuevas centralidades, entendido como un proceso no restringido al centro urbano, sino a la capacidad de articular flujos de todo tipo (acumulación de actividades, intercambio de bienes y servicios, ventajas de la vida urbana, entre otros).

${ }^{17}$ Como efecto secundario, pero no menos importante, estas grandes intervenciones urbanas están generando una alta dispersión de la población sobre el espacio territorial de ambas ciudades.
} 
radicales en la reconfiguración de sus morfologías, reconstitución del tejido urbano y la emergencia de nuevas áreas de recualificación. Enfrentadas, una ciudad pareciera ser la extensión de la otra. Ligado al tratamiento costero han emergido nuevos espacios públicos de alta calidad, al tiempo en que se ha creado un paisaje artificial del que carecían estas ciudades. Desde la planificación urbana en su conjunto, se señala que estas situaciones constituyen nuevas oportunidades para la reconversión de diversas e inéditas actividades productivas y sociales (Brites, 2014; 2016).

El cambio del entorno fluvial, así como el avance de nuevas ordenanzas de planificación y usos del suelo, han dado lugar a procesos de revalorización urbana que en los últimos años empuja una marcada presión inmobiliaria sobre aquellos barrios populares -o partes de ellos-, como Mboi Ka'ê y Pacu Cuá en Encarnación y Chacras y asentamientos ubicados en áreas de la costa oeste y la línea de costa este en Posadas; áreas donde aún residen conjuntos sociales caracterizados por situaciones de vulnerabilidad socioeconómica. Al margen de que muchas barriadas han sido removidas por programas de relocalización, otras han cambiado vía procesos de gentrificación, como en Posadas los viejos barrios: Villa Blosset, la Bajada Vieja, El Brete, etc.

Como ya se ha demostrado en otros trabajos (Brites, 2016; Souza y Brites, 2017, las nuevas formas de desplazamiento más allá de implicar una sustitución socialresidencial de los nuevos espacios, está implicando una transformación económica, en la medida en que requiere de inversiones para la compra y rehabilitación de áreas deprimidas mediante la construcción de nuevas edificaciones residenciales.

Conjuntamente a los aspectos referidos a la revalorización del frente costero, merece señalar que estas ciudades están escenificado nuevos procesos y problemas como los relativos a la extensión del territorio periurbano, el crecimiento poblacional, la articulación de flujos y movilidades interurbanas, ampliación de distancias, urbanización desigual, periferización y dualización espacial; una transformación que pone de relieve signos de fragmentación, división y desigualdades socioespaciales.

De forma resumida la Tabla 2 señala los complejos procesos socioespaciales que caracterizan hoy a Posadas y Encarnación.

Las ciudades de Posadas y Encarnación aprovechan las estructuras de oportunidades vinculadas a la frontera, en un juego complejo de competencias, articulaciones y complementariedades que tiende a transformar ambas ciudades en una conurbación internacional. Así, más allá de las relaciones económicas (asimétricas y cambiantes), la existencia de relaciones entre las funciones urbanas desempeñadas por estas ciudades y sus flujos interurbanos les otorgan características muy singulares.

Aunque la actividad comercial es de vital importancia para la economía de la ciudad, no obstante Encarnación no es del todo una ciudad mono funcional o ciudadshopping, el crecimiento de los servicios, el desarrollo de un polo universitario regional, la ejecución de obras de infraestructuras de Yacyretá, la apertura de extensas playas sobre el río, así como de nuevos espacios de ocio, ha posibilitado una reconversión hacia el turismo como actividad productiva de la ciudad en el contexto regional; por lo que, el perfil económico de Encarnación ha cambiado. Recientemente este nuevo perfil urbano de la ciudad ha quedado plasmado en los lineamientos del Plan Encarnación Más (2016), que plantea un Ordenamiento Urbano-Territorial, así como propuestas de ciudad fluvial, ciudad del comercio y ciudad del turismo, recuperando la impronta paisajística y renovada de la nueva ciudad. 
Tabla 2. Cambios urbanos en Posadas-Encarnación

\begin{tabular}{|c|c|c|}
\hline Nuevos procesos & Posadas & Encarnación \\
\hline $\begin{array}{l}\text { La habilitación de espacios urbanos } \\
\text { revalorizados y de alto valor económi- } \\
\text { co y social, donde residen de manera } \\
\text { casi exclusiva los sectores de mayores } \\
\text { ingresos. }\end{array}$ & $\begin{array}{l}\text { La costanera, el centro y las áreas } \\
\text { adyacentes. Otros espacios habili- } \\
\text { tados en proximidad al río Paraná. }\end{array}$ & $\begin{array}{l}\text { El centro y la tradicional } \\
\text { zona alta. Espacios próxi- } \\
\text { mos a la nueva costanera } \\
\text { sobre el río. }\end{array}$ \\
\hline $\begin{array}{l}\text { Zonas poco integradas a la trama urba- } \\
\text { na y, por lo tanto, a las oportunidades } \\
\text { que brinda el espacio urbano. }\end{array}$ & $\begin{array}{l}\text { La periferia sur, donde se locali- } \\
\text { zan los conjuntos habitacionales, } \\
\text { y barrios pobres, en los límites del } \\
\text { municipio. Fracciones del sector } \\
\text { suroeste. Áreas lindantes al muni- } \\
\text { cipio de Garupá. }\end{array}$ & $\begin{array}{l}\text { La zona noroeste, Itá paso, } \\
\text { San Isidro, arroyo Porá, } \\
\text { Los Arrabales. Cambyretá y } \\
\text { Carmen del Paraná, donde } \\
\text { fue relocalizada población } \\
\text { afectada por la presa. }\end{array}$ \\
\hline $\begin{array}{l}\text { La dependencia del transporte urbano, } \\
\text { los costos en tiempo y en dinero para } \\
\text { trasladarse en la ciudad. }\end{array}$ & $\begin{array}{l}\text { El eje sur, suroeste de la ciudad, } \\
\text { donde residen mayormente los } \\
\text { sectores populares. }\end{array}$ & $\begin{array}{l}\text { La zona norte, noroeste pe- } \\
\text { ri-urbana, donde se localiza } \\
\text { la población de menor po- } \\
\text { der adquisitivo. }\end{array}$ \\
\hline $\begin{array}{l}\text { La emergencia de complejos habita- } \\
\text { cionales. }\end{array}$ & $\begin{array}{l}\text { Población que viven en conjuntos } \\
\text { habitacionales del Instituto Provi- } \\
\text { dencial de Desarrollo Habitacional } \\
\text { (IPRODHA), pero también en los } \\
\text { conjuntos construidos por la Enti- } \\
\text { dad Binacional Yacyretá (EBY). }\end{array}$ & $\begin{array}{l}\text { La política habitacional de } \\
\text { Estado paraguayo es escasa. } \\
\text { Pero la EBY ha construido } 6 \\
854 \text { viviendas para la pobla- } \\
\text { ción afectada. }\end{array}$ \\
\hline $\begin{array}{l}\text { Nuevas centralidades. } \\
\text { Reconfiguraciones urbanas. }\end{array}$ & $\begin{array}{l}\text { Articulación de la zona céntrica } \\
\text { con tramos de Costanera. Mes- } \\
\text { colanzas de usos del suelo: resi- } \\
\text { dencial, espacios productivos y } \\
\text { espacios públicos, esparcimiento, } \\
\text { entre otros. }\end{array}$ & $\begin{array}{l}\text { Nuevo circuito comercial. } \\
\text { Desaparición de la zona } \\
\text { baja y densificación de la } \\
\text { zona alta. Habilitación de } \\
\text { zonas de costas, playas y } \\
\text { reconversión al turismo. }\end{array}$ \\
\hline
\end{tabular}

Fuente: Elaboración propia.

Por otro lado, Posadas casi triplicando las dimensiones urbanas de Encarnación ha consolidado su carácter de centro urbano regional, posicionándose como ciudad universitaria (público-privada), centro de administración pública, de servicios y salud de referencia. ${ }^{18}$ Además, las obras de infraestructura generadas por el efecto Yacyretá han abierto nuevos espacios públicos de esparcimiento de alta calidad, dinamizando el desarrollo de emprendimientos inmobiliarios y nuevas plusvalías urbanas. El conjunto de estas situaciones están haciendo más polivalente y dinámica la vida urbana en estas ciudades (Figura 6).

\footnotetext{
${ }^{18}$ En atención médica, el sistema sanitario público-privado de Posadas es un centro de referencia para los estudios de alta complejidad tanto para residentes del interior provincial como para ciudadanos de Encarnación y otras ciudades adyacentes.
} 
Figura 6. Procesos urbanos y socioespaciales compartidos Posadas-Encarnación

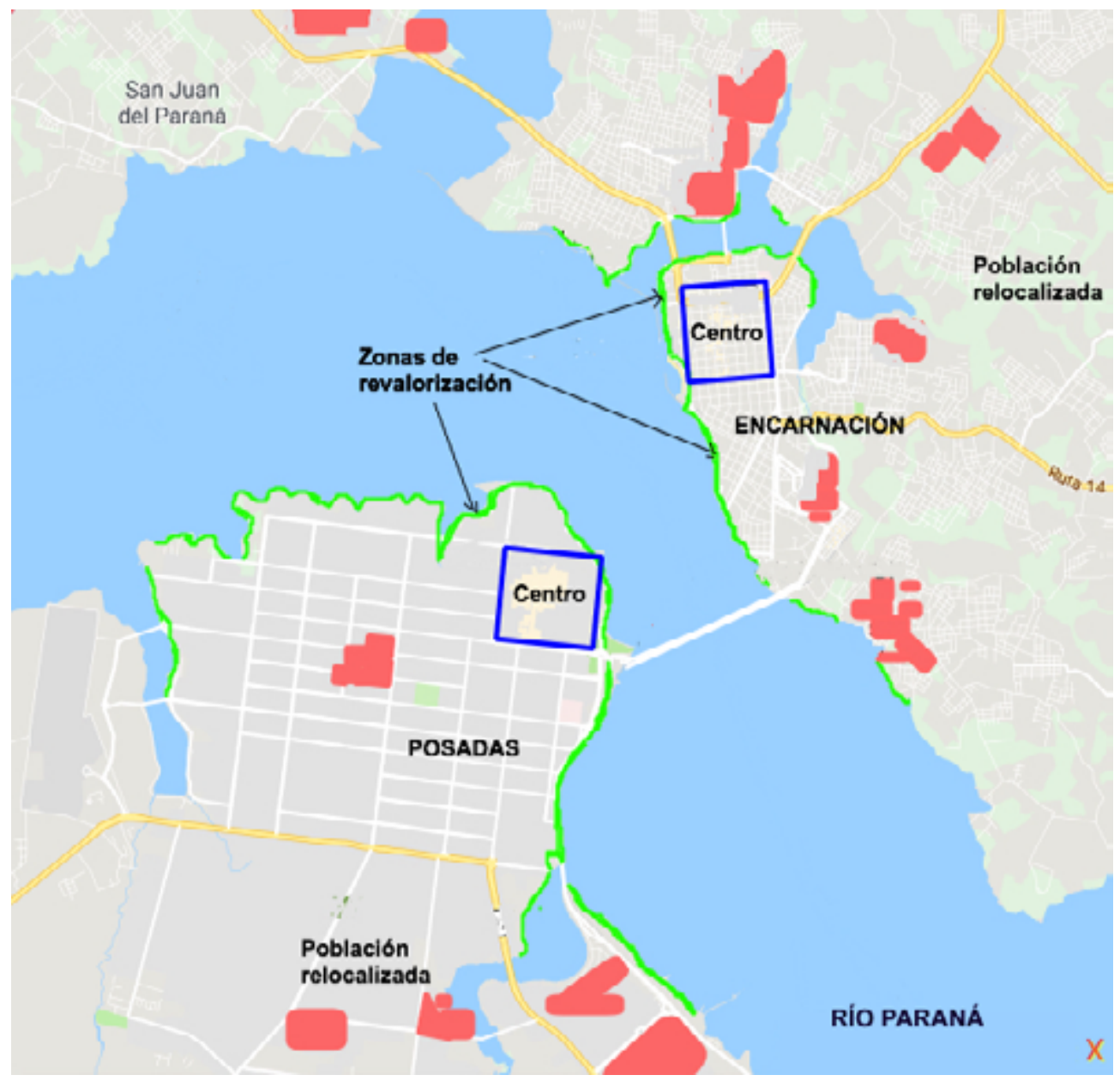

Fuente: Elaboración propia en base a Wikimapia.

Actualmente en la ciudad de Encarnación, llama la atención no solo el desarrollo de su nuevo frente costero, sino el incremento de su infraestructura turística como la hotelera, complejos recreativos, shopping center, y otros. La apertura de grandes playas a la vera del Paraná está posicionando a Encarnación como la ciudad veraniega de Paraguay, ${ }^{19}$ a la vez que oficia junto a la Costanera como un espacio para el encuentro entre posadeños y encarnacenos. Una situación que se desarrolla a la par del mejoramiento de espacios para grandes eventos como "los carnavales", a partir de la construcción del nuevo "sambódromo" y centro cívico, destinado a masivas

${ }^{19}$ Conjuntamente a la costanera, el río Paraná no solo es explotado en términos de actividades náuticas: paseos en lanchas, esquí náutico y wakeboards, sino que ofrece paisajes, atardeceres y espacios de ocio al aire libre. 
concurrencias en los meses de verano. Por otro lado, a nivel del turismo comienzan a visualizarse situaciones de aprovechamiento de la proximidad y la frontera: visitantes que llegan a Posadas aprovechan para pasarse a Encarnación y viceversa. Un hecho que ofrece pistas para pensar nuevas hipótesis en torno a un sistema interactivo de competencias, oportunidades y complementariedades entre las dos ciudades.

Posadas y Encarnación son ciudades "próximas y vinculadas", con procesos urbanos compartidos, donde los cambios socioespaciales y urbanísticos están conllevando nuevas disposiciones, prácticas sociales, estilos de ocio y recreación. La disponibilidad de un sistema de transporte urbano internacional, contribuye a las oportunidades de vinculación entre Posadas y Encarnación (incremento del flujo de personas, realización de actividades, consumo de servicios, etc.). Por otro lado, las áreas neurálgicas de estas ciudades, es decir, sus centros urbanos están dispuestos en unas distancias considerablemente cortas. Sus áreas de renovación urbana (costanera) se encuentran enfrentadas, y vinculados a estos espacios; ambas ciudades escenifican a diario nuevos procesos urbanísticos y sociales, edificios vanguardistas, espacios para deportes, bicisendas, circuitos gastronómicos, bares, pubs, discotecas, lo que dinamiza un conjunto de nuevas actividades urbanas que emergen en paralelo.

\section{Conclusiones}

Posadas y Encarnación comparten una historia de relaciones en el contexto regional, atravesadas por fluidas interacciones económicas y eventos sociopolíticos, donde los procesos de relacionamiento y vinculación funcionan desde hace tiempo. Al margen de sus especificidades, ambas ciudades presentan aspectos sociourbanos similares, y en su devenir estuvieron implicadas en los mismos procesos y problemas: flujos fronterizos, políticas del Mercosur, construcción del puente Internacional, acuerdos de Tránsito Vecinal Fronterizo, y hasta un fenómeno más inusual, como la impronta que el tratamiento costero de Yacyretá ha dejado en sus territorios.

Hemos planteado que los procesos de relacionamientos complementarios refieren a la convergencia de situaciones, experiencias y prácticas sociales, amalgamadas a la cuestión sociourbana transfronteriza. Las infraestructuras, los intercambios comerciales, las racionalidades en torno a las estructuras de oportunidades, las movilidades, los vínculos asociativos, los problemas compartidos, la construcción de agendas en común, entre otros fenómenos, ponen de relieve que estas ciudades se desarrollan manteniendo procesos complementarios de articulación sociourbana.

A pesar de las restrictivas regulaciones económicas y de los mercados por parte de Argentina y Paraguay, ambas ciudades — por su lado—, experimentan localmente la frontera y mantienen intensas interacciones comerciales (formales o informales, con recreadas prácticas para el intercambio). Un ida y vuelta en el que las ganancias diferenciales y complementariedades las mantienen en tensiones y conflictos, pero unidas y en interacción. Puede decirse, que las tensiones y competencias que existen, en mayor medida se derivan de un ámbito particular del mercado laboral fronterizo: el vinculado al sector comercial, una tensión que está sujeta a coyunturas económicas, equilibrios inestables, procesos de acumulación diferencial, y que con frecuencia escapan al control de las políticas fronterizas. 
Como ciudades cercanas y enfrentadas entre sí, el modelo de ciudades gemelas, resulta conveniente para describir sus relaciones y referirse a algunos puntos en común entre ambas. La circulación de personas, mercaderías e informaciones, los espacios de flujos habilitados, los procesos socioeconómicos, y las estructuras de oportunidades, constituyen circunstancias regulares, que se fusionan a la dimensión físico territorial, donde la interacción interurbana transfronteriza se vuelve crucial.

La intensa articulación interurbana es compleja y amalgamada a lo multipropósito, donde lo comercial, lo laboral, lo educativo, lo recreativo y hasta lo familiar, juegan un papel importante. Aunque compiten y cooperan, ambas ciudades comparten hoy nuevos desafíos, como el intercambio desigual, el crecimiento extensivo del territorio, el desarrollo urbano fragmentado y la necesidad de una mejor vinculación entre ambas. Precisamente esta última, con foco en la necesidad de un "puente más ágil", ejemplifica acertadamente el agobio de mutuos reclamos y expectativas.

A pesar de las tensiones y competencias (por las asimetrías económicas), las relaciones de complementación entre ambas ciudades conllevan potenciales beneficios, acorde a las ventajas diferenciales que ofrece la frontera. Los ciudadanos de ambas partes urbanas no solo pueden adquirir productos y acceder a servicios, sino que la interacción entre la población aumenta y facilita intercambios sociales, educativos y culturales. El relacionamiento sostenido y la "vivencia diaria" mejoran la comprensión mutua entre habitantes que cotidianamente tienen la idiosincrasia de compartir y vivir localmente la frontera.

\section{Referencias}

Abínzano, R. (1985). Procesos de integración en una sociedad multiétnica: La provincia Argentina de Misiones (Tesis doctoral). Universidad de Sevilla, España.

Acuña, B. y Graizbord, B. (1999). Movilidad cotidiana de trabajadores en el ámbito megalopolitano de la Ciudad de México. En J. Delgado y B. Ramírez (Coords.), Territorio y cultura en la Ciudad de México (Tomo 1: Transiciones, pp. 195-207). México: Universidad Autónoma Metroplitana, Plaza y Valdez Editores.

Alegría, T. (2008). ¿Existen las metrópolis transfronterizas? El caso de Tijuana/San Diego. En H. Dilla (Coord.), Ciudades en la frontera: Aproximaciones críticas a los complejos ubanos transfronterizos (pp. 127-166). Santo Domingo, República Dominicana: Editora Manatí.

Ascher, F. (2001). La nouvelle révolution urbaine: De la planification au management stratégique urbain. En A. Masboungi (Coord.), Fabriquer la ville. Outils et méthodes: Les aménageurs proposent (pp. 21-32). París, Francia: La Documentation française.

Báez, A., Brites, W. y Espinoza, J. (Septiembre, 2013). Vida cotidiana en complejos urbanos transfronterizos. El caso de Posadas (Misiones, Argentina) y Encarnación (Itapúa, Paraguay). Trabajo presentado en el xxix Congreso ALAs Asociación Latinoamericana de Sociología, Universidad de Chile, Santiago de Chile.

Bartolomé, L. (1983). Aspectos Sociales de la Relocalización de la Población Afectada por la Construcción de Grandes Represas. Documento Base para el Seminario Interamericano sobre Efectos Sociales de las Grandes Represas en América Latina. Buenos Aires, Argentina: Centro Interamericano para el Desarrollo Social (oEA y Naciones Unidas). 
Benedetti, A. (2011). Lugares de frontera y movilidades comerciales en el sur sudamericano. Una aproximación multiescalar. En E. A. Costa, G. V. L. Costa y M. A. M. Oliveira (Orgs.), Fronteiras em foco (pp. 33-55). Campo Grande, Brasil: 3 Série Fronteira. Editora da UfMs.

Brites, W. (2014). La mega-hidroeléctrica Yacyretá en el vórtice de las reconfiguraciones urbanas. El caso de las ciudades de Posadas, Argentina y Encarnación, Paraguay. URBS. Revista de Estudios Urbanos y Ciencias Sociales, 4(2), 91-107.

Brites, W. (2016). New urban processes in Encarnación city, Paraguay: The waterfront development and urban renewal. En M. Gyurkovich, J. Cladera y R. Biere (Eds.), Back to sense of the city (pp. 263-273). Cracovia, Polonia: Publishing Centre of Land Policy and Valuations (CPSv), 11 CTV.

Bustamante, J. (1981). La interacción social en la frontera México-Estados Unidos: Un marco conceptual para la investigación. En R. González (Ed.), La frontera norte: Integración y desarrollo (pp. 23-42). México: El Colegio de México.

Buursink, J. (2001). The binational reality of border crossing-cities. GeoJournal, 54(1), 7-19. doi: https://doi.org/10.1023/A:1021180329607

Carrión, F. (17 de febrero de 2016). Ciudades de frontera en América Latina. El País. Recuperado de https://elpais.com/elpais/2016/02/17/seres_urbanos/1455692400_145569.html

Carrión, F. y Llugsha, V. (2013). Introducción. La frontera: Inseguridad por desencuentro de diferencias. En F. Carrión y V. Llugsha (Comp.), Fronteras: Rupturas y convergencias (Colección Fronteras, pp. 9-28). Quito, Ecuador: Flacso, IDRCCDRI.

Comisión Nacional de Regulación del Transporte (CNRT). (2017). Informe Estadístico Anual 2017. Red Ferroviaria de Pasajeros Regionales de Larga Distancia. Argentina: Ministerio de Transporte Presidencia de la Nación.

Cossi, C. A. (2013). Continuidades y discontinuidades en los márgenes. Paso fronterizo Posadas-Encarnación. La Rivada, 1(1), 1-23.

Dilla, H. (2008). Los complejos urbanos transfronterizos en la frontera dominico-haitiana. En H. Dilla (Coord.), Ciudades en la frontera: Aproximaciones críticas a los complejos urbanos transfronterizos (pp. 167-204). República Dominicana: Fundación Ford, CIECA, PADF, UNIBE.

Dilla, H. (2015). Los complejos urbanos en la frontera dominico-haitiana. Aldea Mundo, 20(39), 43-53.

Dirección General de Estadísticas, Encuestas y Censos (DGEEc). (2015). Paraguay. Proyección de la población por sexo y edad, según distrito, 2000-2025. Asunción, Paraguay: Secretaría Técnica de Planificación del Desarrollo Económico y Social.

Dirección Nacional de Migraciones (DNM). (2017). Panorama movimientos migratorios. Recuperado de http://www.migraciones.gov.ar/pdf_varios/estadisticas/movimientos_migratorios_2017.pdf

Ehlers, N., Buursink, J. y Boekema, F. (2001). Introduction. Binational cities and their regions: Form diverging cases to a common research agenda. Geojournal, 1(54), $1-5$.

Herzog, L. A. (1990). Border commuter workers and transfrontier metropolitan structure along the United States-Mexico border. Journal of Borderlands Studies, V(2), $1-20$. 
Instituto Provincial de Estadísticas y Censos (IPEC). (2010). Anuario estadístico de Misiones. Posadas, Argentina: Autor.

Kearney, M. y Knopp, A. (1995). Border cuates: A history of the U.S.-Mexican twin cities. Austin, Texas: Eakin Press.

Linares, M. D. (2017). Nuevos paisajes urbanos en la frontera: Las "paseras" paraguayas entre Posadas (Argentina) y Encarnación (Paraguay) y el plan de obras de Yacyretá (2009-2010). Si Somos Americanos, Revista de Estudios Transfronterizos, $17(1), 65-94$.

Lungo, M. (2011). Grandes proyectos urbanos: Una visión general. En M. Lungo (Ed.), América Latina: Países pequeños de grandes ciudades (Colección Textos Urbanos volumen x, pp. 93-138). Quito, Ecuador: Organización Latinoamericana y del Caribe de Centros Históricos.

Mikhailova. E. (2013). Appearance and appliance of the twin-cities concept on the Russian-Chinese border. En The International Archives of the Photogrammetry, Remote Sensing and Spatial Information Sciences, XL-4/W3, pp. 105-110.

Ojeda, N. (2008). Reflexiones acerca de las familias transfronterizas y las familias transnacionales entre México y Estados Unidos. Frontera Norte, 21(42), 7-30.

Organización Internacional para las Migraciones (оIM). (2018). Dinámicas migratorias en fronteras de países de América del Sur. Cuadernos Migratorios, (10).

Peña, S. (2008). Ciudades y fronteras: Los retos de la planificación transfronteriza. En H. Dilla (Coord.), Ciudades en la frontera: Aproximaciones críticas a los complejos urbanos transfronterizos (pp. 263-282). República Dominicana: Fundación Ford, CIECA, PADF, UNIBE.

Plan Encarnación Más. Plan de Desarrollo Sustentable y Plan de Ordenamiento Urbano y Territorial. Documento director. (2016). Recuperado de https://www.dropbox.com/s/ cfmmf7g48ro7dmn/EncarnacionMas_DocumentoDirector_v1.0.pdf?dl=0

Plan Estratégico Posadas 2022. (2010). Recuperado de https://www.mininterior.gov.ar/ planificacion/pdf/planes-loc/MISIONES/Plan-Estrategico-Posadas-2022.pdf

Plan Urbano Ambiental Posadas. (2012). Recuperado de http://planurbano.posadas. gov.ar/plan-urbano-ambiental-posadas/

Pobreza urbana (Pobur). (1989). Determinantes estructurales y estrategias adaptativas de la pobreza urbana. México: Secretaría de investigación, Universidad Nacional de Misiones, Conicet.

Souza, E. C. de y Brites, W. F. (2017). Dinámicas urbanas en ciudades gemelas impactadas por hidroeléctricas. Revista Terr@Plural, 11(2), 271-290.

Steiman, R. (2012). Zona de fronteira e cidades gêmeas: Uma tipologia das interações transfronteiriças. En C. G. Zárate (Ed.), Espacios urbanos y sociedades transfronterizas en la Amazonia (pp. 154-167). Colombia: Universidad Nacional de Colombia, Instituto Amazónico de Investigaciones.

Tambi, S. (2016). The contemporary development of the concept of the twin cities: The case of cross-border cooperation between Narva and Ivangorod (Tesis de maestría). University of Tartu, Estonia.

Vanneph, A. y Revel-Mouroz, J. (1994). Ciudades fronterizas México- Estados Unidos. Estudios Fronterizos, (33), 9-35.

Vergel-Tovar, E. (2008). Ciudades gemelas en fronteras amazónicas: Estudio de caso Leticia y Tabatinga. Cuadernos de Vivienda y Urbanismo, 1(2), 348-393. 
Zárate, C. G. (2012). Ciudades pares en la frontera amazónica colonial y republicana. En C. G. Zárate (Ed.), Espacios urbanos y sociedades transfronterizas en la Amazonia (pp. 21-44). Amazonas, Colombia: Universidad Nacional de Colombia, Instituto Amazónico de Investigaciones.

Zavaleta, A. (1986). The twin cities: A historical synthesis of the socio-economic interdependence of the Brownsville-Matamoros border community. En M. Kearney (Ed.), Studies in Brownsville history, Brownsville (pp. 125-171). Texas, Estados Unidos: Pan American University at Brownsville Press.

\section{Material legislativo}

MERCOSUR/RMI/ACORDO $\mathrm{N}^{\circ}$. 17/99. Acuerdo sobre transito vecinal fronterizo entre los Estados parte del Mercosur. (s.f.). Recuperado de http://www.sice.oas.org/ trade/mrcsrs/decisions/dec1899s.asp

Ley No 2422. Código Aduanero. Congreso de la Nación Paraguaya sanciona con fuerza de ley. (2004). Recuperado de http://www.aduana.gov.py/uploads/archivos/ codigo\%20aduanero.pdf

Resolución General o 262, Administración Federal de Ingresos Públicos. (1998). Recuperado de http://biblioteca.afip.gob.ar/dcp/REAG01000262_1998_11_13

Resolución General № 1116, Administración Federal de Ingresos Públicos. (2001). Recuperado de http://biblioteca.afip.gob.ar/dcp/REAG01001116_2001_10_17

Walter Fernando Brites

Argentino. Doctor en Antropología Social (2012) y Master en Políticas Sociales (2006). Universidad Nacional de Misiones. Investigador Adjunto en el Consejo Nacional de Investigaciones Científicas y Técnicas (Conicet) y el Instituto de Estudios Sociales y Humanos iesyh-unam, Argentina. Líneas de investigación: políticas y procesos sociourbanos en ciudades. Entre sus publicaciones recientes: F. Brites y M. R. Catullo (comps.). (2017). Ciudades, desarrollo y consecuencias sociales de grandes proyectos. Experiencias regionales en análisis (2017). Asunción, Paraguay: Divesper. ISBN: 978-99967888-1-9. 